\title{
Application of Numerical Simulation in Optimized Lighting Design of Industrial Buildings
}

\author{
Yannan Huo ${ }^{1, a}$, Wei $\mathrm{Li}^{1, \mathrm{~b}}$ and Yan Wang ${ }^{2, \mathrm{c}}$ \\ ${ }^{1}$ Institute of Green Architecture Technology and Application, Tianjin Chengjian University, Jinjing \\ Street, Tianjin, China \\ 2Zhejiang South Architectural Design Co.,Ltd, 34\#No.36 Baiyun Road, Hangzhou \\ a2510338803@qq.com, bliweiliwei75@126.com, csouthhb@126.com
}

\begin{abstract}
Keywords: Industrial buildings, daylighting optimization, numerical simulation
Abstract. A workshop located in Tianjin suburb is selected using computer numerical simulation technique to study the indoor daylighting. The original daylighting design and optimized design are simulated and the leading indicators of natural light are compared and analyzed. Research results show that compared with that of the original daylighting design, daylighting of the optimized design come up to the national standard. Meanwhile, the area of the daylighting opening is reduced by $83.33 \%$, which improves the lighting efficacy while greatly reducing heat transmission of the building envelop.
\end{abstract}

\section{Introduction}

With the popularity and development of Green Building concepts, natural lighting design with dual functions of energy saving and comfort is getting more and more attention. Especially for industrial buildings, as the processing precision of their working objects is often higher, the natural lighting environment has an important influence on production efficiency. A good natural lighting environment is very beneficial to workers' vision health and their efficiency.

However, due to the fact that the volume of industrial factories is often quite large, when architects design daylighting hole, it is difficult to reasonably arrange the number and location of daylighting outlets, so that the indoor natural illumination reaches national standards. In the design practice, there are often situations where the area, number, and location of daylight outlets are set arbitrarily, which results in insufficient or excessive daylighting, and fail to meet the lighting standard.

To solve the above mentioned problems, the numerical simulation software is used to verify and optimize the lighting design scheme. With the advantages of high accuracy and being easy to modify and optimize, this method is of great guiding significance to the architectural lighting schemes.

In this paper, the building performance integrated simulation software (IES) is used to verify and optimize the lighting design of an industrial plant in the suburb of Tianjin. By analyzing the simulation data, the optimal lighting design scheme of the plant will be proposed.

\section{Numerical Simulation and Optimization of the Lighting Design Schemes}

The numerical simulation software used in this paper is the lighting analysis module in IES. The analysis and evaluation standard adopted is the national standard of the People's Republic of China the Architectural Lighting Design Standard GB50033-2013 (hereinafter referred to standard).

The industrial plant in this study is located in the suburb of Tianjin and is mainly engaged in the processing of precision equipment. The width of the workshop is 96.8 meters, the depth 24.4 meters, the indoor clear height 5.4 meters.

Simulation analysis of lighting effects of original architectural plan.In the original architectural plan, side windows were used for lighting. A total of 27 side windows were opened on the north and south facades of the plant, each with an area of $8 \mathrm{~m}^{2}$ and a total lighting area of $216 \mathrm{~m}^{2}$.

Figure 1 shows the numerical simulation results of the original lighting scheme. 

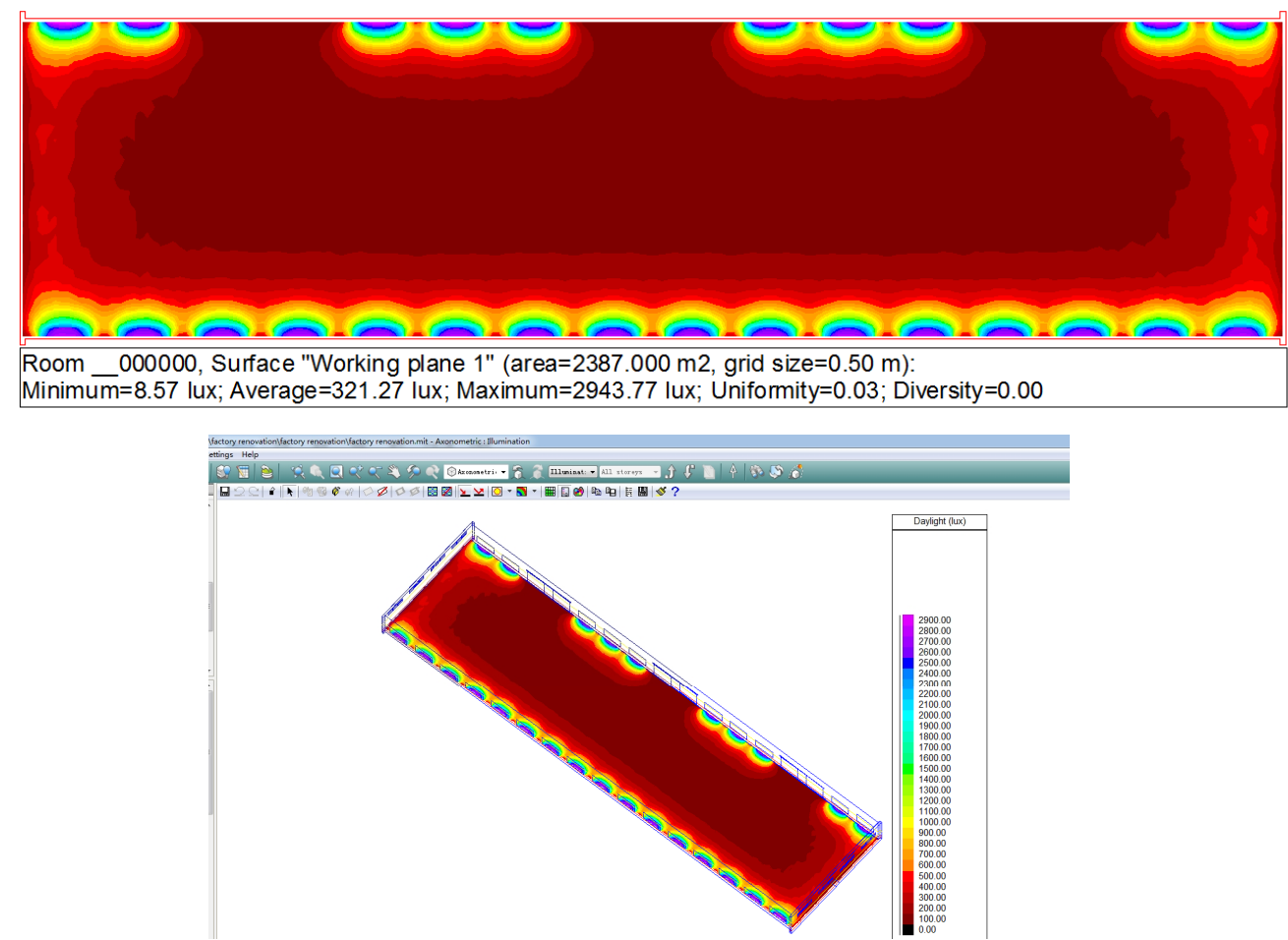

Figure1 Numerical simulation results of side window lighting in the original scheme

As it can be seen from Figure 1, with only side-window lighting, the natural lighting evaluation value within the factory building is only $321 \mathrm{~lx}$, which is far below the stipulated illuminance value of the national standard (for workshops engaged in precision equipment processing, the required average illuminance value of indoor daylighting should reach $600 \mathrm{~lx}$ when the side windows are adopted), and the illuminance value of most areas is only about $50 \mathrm{~lx}$ as the central area of the workshop is far from the side windows.

In order to improve the natural illumination of the central area of the factory, the designer design another way of lighting, which is to add skylight lighting. Two consecutive rectangular sunroofs are opened in the middle area of the roof of the factory building, and the area of each sunroof is $450 \mathrm{~m}^{2}$, a total area $900 \mathrm{~m}^{2}$.

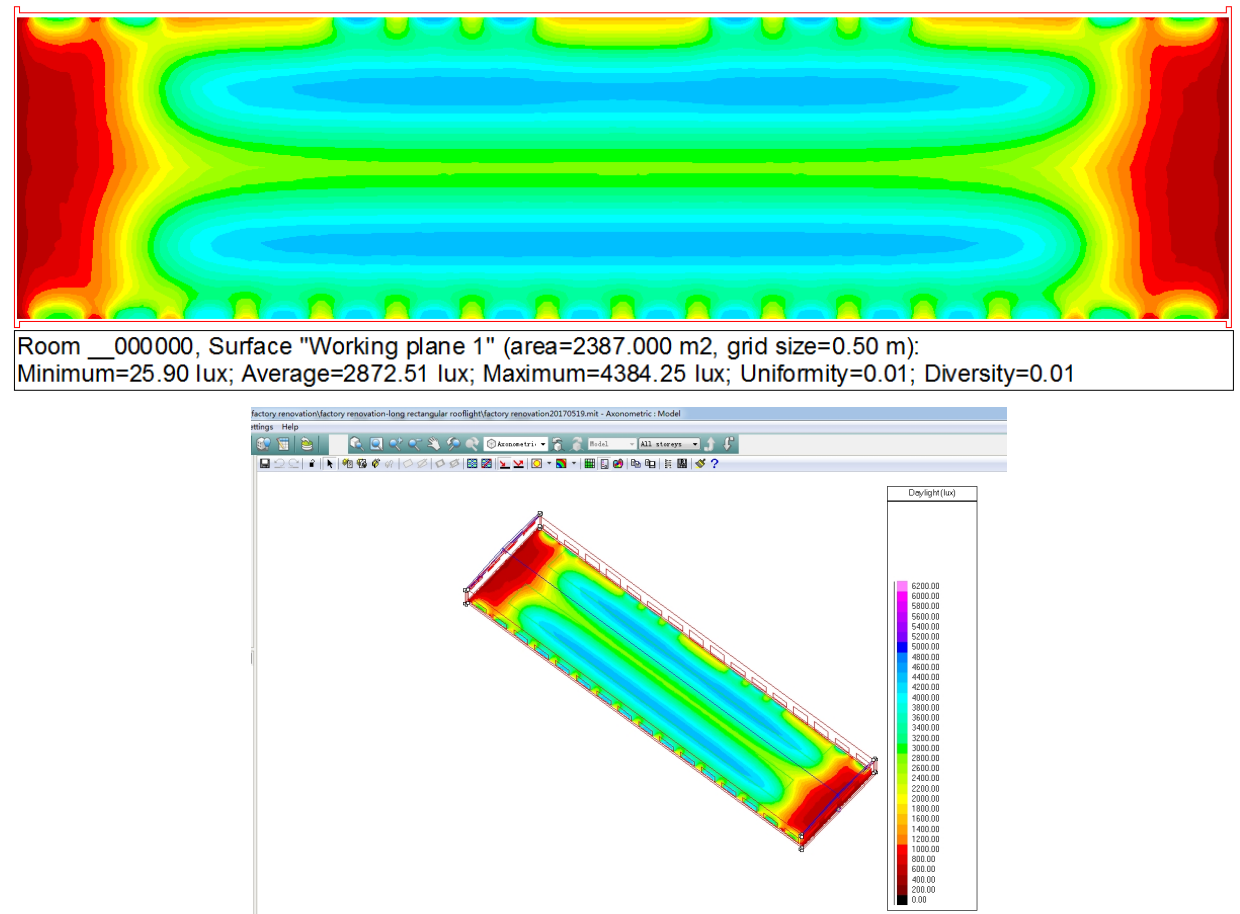

Figure 2 Numerical simulation results after adding sunroof 
From the simulation results in Figure 2, it can be seen that the average illuminance value in the factory building is $2872 \mathrm{~lx}$ and the uniformity is 0.01 . According to the requirements of the standard, the indoor natural illuminance value of this type of factory building with top lighting should reach 450 $\mathrm{lx}$, and the numerical value of the simulation result far exceeds the standard requirement. In this case, it results in not only glare, but also increased heat transfer load because of the large area of skylight, which fails to meet the energy-saving requirement.

Numerical simulation of the optimized lighting scheme. In order to avoid excessive lighting and reduce the heat transfer load of the envelope structure, the form of the skylight of the building was optimized: each of the original continuous rectangular skylight is rearranged as 10 independent skylights, and the size of each skylight is $2.5 \mathrm{~m} \times 3.5 \mathrm{~m}$, the area $7.5 \mathrm{~m}^{2}$. After optimization, a total of twenty $7.5 \mathrm{~m}^{2}$ scattered skylights were installed on the roof, reducing the total lighting area from 900 $\mathrm{m}^{2}$ to $150 \mathrm{~m}^{2}$. The numerical simulation results of the new lighting scheme are shown in Figure 3 .
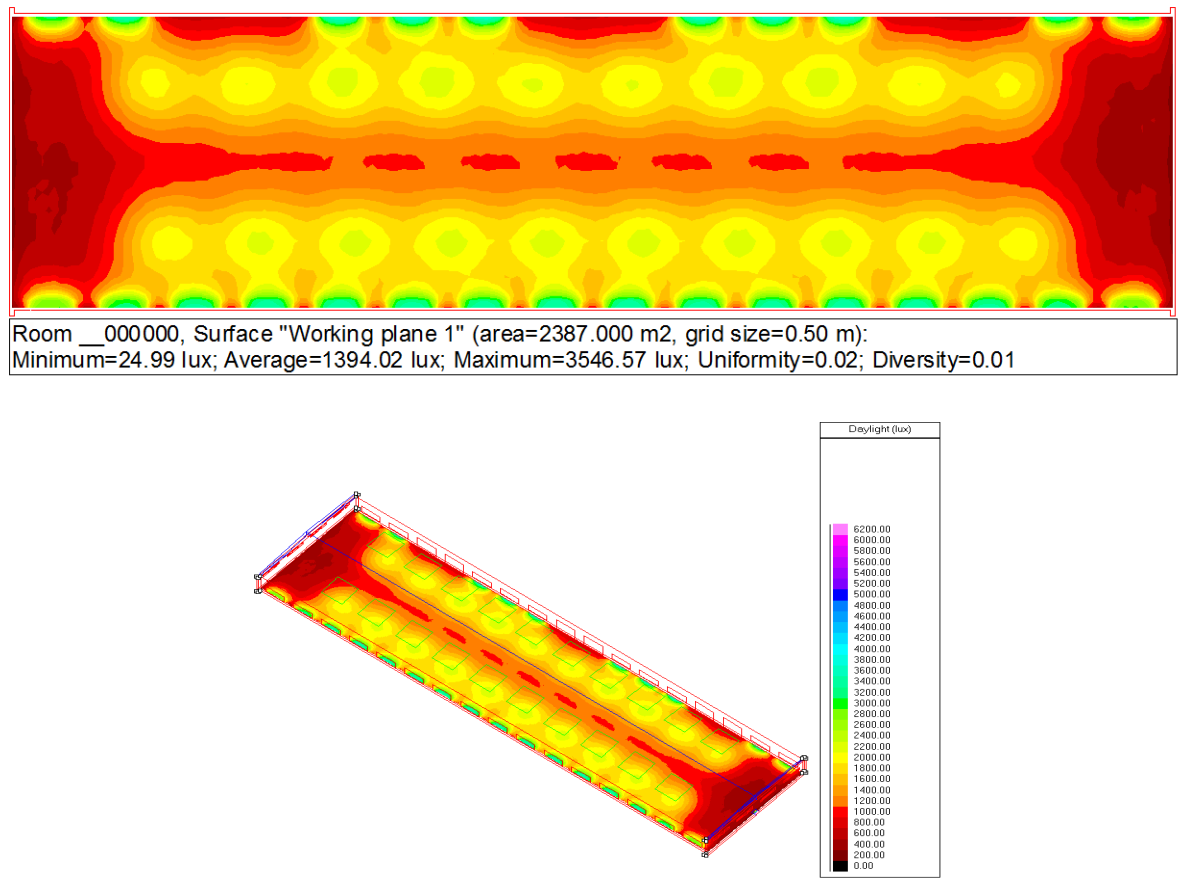

Figure 3 Numerical simulation of decentralized natural lighting effects

From the simulation results in Figure 3, it can be seen that the average value of natural illuminance in the factory building is $1394 \mathrm{~lx}$, and the uniformity is 0.02 . Compared with the original lighting scheme of adopting two consecutive rectangular skylights, the illuminance value of the present scheme decreased by $1478 \mathrm{~lx}$, while the uniformity increased by $100 \%$. According to the national standards, The daylighting from the decentralized sunroof still meets the requirements, while the lighting area is greatly reduced to $1 / 6$ of that of the original sunroof. This greatly reduces the heat transfer load of the envelope structure and is ideal for the lighting program.

As for the natural illuminance alone, the illuminance value of the daylighting from the distributed skylights with a total area of $150 \mathrm{~m}^{2}$ still exceeds that of the national standard (450 lx), and there is still room for further optimization from a numerical point of view. However, after simulation, it shows that if the area of the daylighting port is further reduced and decentralized, the daylighting unformity of the middle area of the workshop will decrease greatly, which will be unforvable to the fine processing of the working face. Therefore, the area of the daylighting port should not be reduced. 


\section{Conclusions}

Due to the huge volume of the industrial plant, the lighting design is relatively complex. It is an ideal way to use the numerical simulation to optimize the lighting design. The research in this paper shows that compared with the continuous skylights commonly used in industrial buildings, the use of decentralized skylights has a better lighting efficiency. Taking the research subject in this study as an example, the area of scattered skylights is only $1 / 6$ of the original area of continuous skylight lighting, which greatly reduces the heat transfer load of the envelope structure while meeting the national standard requirement in terms of illuminance.

\section{Acknowledgements}

This work was supported by Tianjin Science and Technology Support Project (Grant Numbers 15ZCZDSF00080); Tianjin Science and Technology Support Project (Grant Numbers 16PTGCCX00060);National Key R\&D Program of China （Grant No.2016YFC0700201 ).

\section{References}

[1] Qianmiao Yang, Hui Gao, Natural Lighting Design of Atrium [J], Architectural Journal, 2007, 09: 68-70

[2] Wei Yan, Integrated Study of Natural Lighting with Space Configuration [J], Architectural Technique, 2009, 06:94-97

[3] Jianhua Ding, Hong Jin, "Green” Regeneration of Old Industrial Buildings [J], New Architecture, 2012, 04:81-85 